\title{
Monitoring Book Reshelving in Libraries Using Statistical Sampling and Control Charts
}

\author{
Jeffrey M. Edwardy and Jeffrey S. Pontius
}

Maintaining library books in their proper locations is resource intensive. Typically shelf reading, where library personnel inspect every book on the shelves, is used to identify and relocate improperly shelved books. We propose a statistical approach to determine when shelf reading of books is necessary. We use sampling to obtain data on misshelved books over time. A control chart is used to assess when shelf reading is necessary. These statistical tools will provide library managers with cost-effective approaches to monitoring and implementing reshelving activities.

T ibraries are keystone knowledge repositories for our communities, universiLties, and global society. To maximize the availability of library resources to patrons, the resources they contain must be organized in a logical system and maintained according to that system. Library managers attempt to use personnel in a way that provides the highest possible standard of resource maintenance at the lowest possible cost. One component of this effort involves the management of those books not shelved in proper sequence relative to other books. As indicated by Flexner, "the ultimate usefulness of any library depends on the ability of the staff and the public to find books on the shelves with ease and assurance" $(1927,233)$. Thus a low number of misshelved books is advantageous for a high standard of resource maintenance and provides "ease and assurance" for patrons. We consider the term "books" to include all usual books, bound and unbound periodicals, government documents, abstracts, indexes, and similar items that are accessible to patrons.

Jeffrey M. Edwardy (JEdwardy@carlson. com) is a Marketing Analyst, Carlson Marketing Group, Measurement and Analysis, Plymouth, Minn.

Jeffrey S. Pontius (pontius@stat.ksu. edu) is Associate Professor, Department of Statistics, Kansas State University, Manhattan, Kans.

Acknowledgement: We thank the referees for their useful comments. In particular, one referee's comments encouraged us to clarify several parts of the manuscript.

Manuscript received October 3, 2000: accepted for publication November 14,2000 .

A common method of monitoring and reshelving misshelved books is called shelf reading (Lowenberg 1989). Employees look at books in specified sections of the library and determine whether the books are in correct call number order. If a book is not in sequence, the employee is supposed to reshelve the book in proper sequence. This procedure is costly in terms of employees' working times, especially if there are few books to reshelve. Several methods have been proposed to assess misshelving rates (Cooper and Wolthausen 1977, SPRouTs). However these methods are not easy to implement and they do not focus on misshelving. Hence, an efficient method to ascertain misshelving rates would be useful to library managers in order to implement shelf-reading programs only when necessary.

We propose using a statistical sampling strategy to estimate the magnitude of misshelving within the library collection. Then based on these estimates, we 
propose using control charts to indicate when shelf reading is necessary. Performance measures that can be used to determine shelving accuracy have been proposed (Kendrick 1991) but performance measures alone do not contain the historical information and decision criteria contained in a control chart. The practical motivation for this study was to provide library managers with efficient, accurate, and easyto-use methods for maintaining books in proper call number sequence within a collection.

The goals of our study were:

- to construct a practical sampling strategy to obtain estimates of the accuracy rates of (non)misshelved books; and

- to provide a statistical assessment tool (control chart) to indicate when shelf reading should be implemented.

Statistical sampling will enable library managers to use personnel more efficiently (especially as compared to randomly implementing shelf reading). Control charts will enable library managers to set objective criteria for shelving accuracy, to monitor shelving accuracy rates over time, and to use these criteria to implement shelf reading only when necessary. In conjunction with the statistical methods, the procedures used in the implementation of the sampling and control charts need to be easily understood by the library managers if they are to be of value. As a result, decisions on sampling strategy protocols and control chart construction were made in cooperation with Kansas State University's Hale Library stacks managers and staff. Although some of the criteria developed herein are specific to Hale Library, the general ideas are applicable to other libraries. The essential result of using the sampling and control chart approach for library managers will be efficient use of the resources that are involved in properly maintaining shelved books.

\section{Sampling Strategy}

Strategies for sampling books in a library have been proposed using the individual book as the sampling unit. To estimate the percentage of lost books in a collection (not specifically misshelved books), Miller and Sorum (1977) used a two-stage sampling design for collecting data on which to compute a confidence interval. Miller and Sorum noted that misshelved books would inflate the estimate of lost books. DiCarlo (1988) used sequential sampling to determine if an inventory of a collection was necessary to retrospectively update the library's catalog system. A sampling method based on selecting individual cards (books) in a card file was originally proposed by Fussler (see Fussler and Simon 1969), and further refined by Bookstein (1983).
Bookstein noted that estimation in Fussler's method should use unequal probabilities of selection, where the probabilities are based on the thicknesses of the cards.

These computations are not easy without the aid of an appropriate computer program. The books in the sample would then be located and classified as misshelved if not located in proper sequence. But locating individual books is time consuming.

\section{Sampling Strategies and Protocols}

We decided to use a shelf of books as the sample unit rather than an individual book. A shelf is a natural, easily identifiable and locatable physical unit. Also one does not have to account for borrowed, circulating, or lost books when selecting a sample of nonempty shelves, as one does with selecting a sample of individual books. At Hale Library, diagrams of shelves that contain books are maintained and updated frequently, so a list of shelves of books is readily available to use as a sampling frame.

To recommend a sampling strategy, we needed some preliminary information on misshelving rates. Because different collections have different frequencies of use and some collections require a very low number of misshelved books (e.g., reference collections), we selected four collections on which to evaluate three candidate sampling strategies. Treating different collections as separate populations allows sampling specifications (e.g., sample size, frequency of inspection) to be tailored to the different collections' characteristics (e.g., frequency of use). The collections (populations) chosen for this study and the misshelving priorities assigned to them by the Hale Library managers were science reference (requires a very low misshelving rate), juvenile literature (a low misshelving rate is not critical), mathematics (high frequency of use), and anthropology (low frequency of use).

We selected three sampling strategies based on their implementation and estimation characteristics (see Thompson 1992, Tryfos 1996, Lohr 1999). We selected simple random sampling without replacement (SRSWOR) of shelves with estimation of the mean number of misshelved books per shelf as our first strategy. This strategy is the simplest and is typically used as the basic strategy with which to compare other strategies. The second strategy was SRSWOR with an estimator of the ratio of the number of misshelved books on a shelf to the number of books on that same shelf. If the number of misshelved books increases as the number of books per shelf increases, the ratio estimator would potentially provide estimates with smaller standard errors than using only the mean number of misshelved books per shelf.

Our third strategy was adaptive cluster sampling (Thompson 1992). In using this strategy, an SRSWOR of 
shelves is selected. If the number of misshelved books on a sampled shelf is two or more, the shelves immediately above and below the sampled shelf are inspected. This process continues on adjacent shelves above or below the shelf last inspected until the above and below shelves contain fewer than two misshelved books. We selected adaptive cluster sampling for two reasons. First, we assumed that once misshelving has begun, subsequent reshelving episodes will likely result in an increasing number of misshelved books that could spill over onto adjacent shelves. Second, we assumed that if a patron cannot find a book because it has been misshelved, he or she is likely to inspect neighboring shelves in an attempt to locate the book.

Our goal was to select the sampling strategy that produced the smallest standard errors across the four collections while keeping the number of shelves to be inspected under the adaptive cluster strategy to a reasonable number. Having one sampling strategy would be easiest for implementation by library personnel. However, different strategies could be used for different collections. To compare the sampling strategies, we took a census of each of the four collections. This entailed inspecting every shelf (that contained at least one book) in each collection and recording both the number of books per shelf and the number of misshelved books per shelf. We defined a misshelved book to be one whose call number was greater than the call number of the adjacent book on its right or less than the call number of the adjacent book on its left. Our definition included identifiers such as volume numbers in a series of bound volumes of a periodical.

\section{Evaluation of Sampling Strategies}

After the census of each collection, we evaluated the sampling strategies based on the data. Thompson (1992) suggests that for adaptive cluster sampling to be more efficient (with smaller standard errors) than SRSWOR with the sample mean, the clusters of shelves with two or more misshelved books should be relatively rare. We did not observe this, so we did not consider adaptive cluster sampling further.

For the ratio estimator to be efficient, it is advantageous to have an approximately linear relationship between the number of misshelved books per shelf and the number of books per shelf. We did not observe a linear relationship in any of the populations (the data appeared as a random scatter in each plot). These observations indicate that the numbers of misshelved books do not necessarily increase as the numbers of shelved books increase. In fact, we did not observe any trends in the ratios of the numbers of misshelved books to the numbers of books per shelf. Apparently misshelving books is not related to the density of books on a shelf, at least for the collections we studied. Perhaps mis- shelving is a result of inexperienced personnel, inattention or fatigue by personnel, or the complexity of some book indexes. Based on these conclusions and on our observations that the relative efficiencies (standard errors of the ratio estimates to the standard errors of the respective sample means) were close to one (see table 1), we recommended SRSWOR with the sample mean as the preferred sampling strategy.

\section{Control Chart}

A control chart is a plot of the values of a statistic (e.g., sample mean) over time (Aczel 1995, Brase and Brase 1998). It is used to track the progress of a process over time. We use a control chart to monitor the estimated accuracy ratings of (non)misshelved books relative to an accuracy rating target value; that is, to monitor the proportion of properly shelved books relative to a target accuracy rating set by the library manager (see figure 1 ). If the accuracy rating estimates fall below a specified minimum acceptable accuracy rating (lower control limit), the library manager can implement shelf reading to bring the reshelving process back into control. Hence, the control chart, based on sampling for misshelved books, provides the library manager with a quantitative method to assess the status of shelved books without the intensive work of shelf reading.

\section{Control Chart to Monitor Reshelving}

We constructed a control chart to monitor the accuracy of properly shelved books using an accuracy rating computed from misshelving data collected by SRSWOR. The accuracy rating $(\hat{A R})$ estimator is

$$
(\hat{\mathrm{AR}})=1-\frac{\overline{\mathrm{y}}}{\mu_{\mathrm{x}}}
$$

where $\bar{y}$ is the mean number of misshelved books from the SRSWOR of $n$ shelves and $\mu_{x}$ is the known mean number of books per shelf in the collection (the total number of books in the collection divided by the total number of nonempty shelves housing the collection). An $\hat{A R}$ near one indicates that there are relatively few misshelved books in the collection. The data necessary to compute $\mu_{x}$ may appear to be difficult to obtain but should be computable when book

\begin{tabular}{|c|c|c|c|}
\hline Anthropology & Juvenile & Mathematics & Science \\
\hline 1.21 & 1.09 & 1.14 & 1.07 \\
\hline
\end{tabular}


indexes are stored in computer databases. Note that a close approximation to $\mu_{x}$ will still yield reasonable $\hat{A R}$ estimates, for example, when some books are circulating. The standard error of $\hat{A R}$ is

$$
\mathrm{SE}(\hat{\mathrm{AR}})=\frac{\mathrm{S}}{\sqrt{\mathrm{n} \mu_{\mathrm{X}}}}
$$

where $s$ is the standard deviation of the number of misshelved books from the SRSWOR of $n$ shelves. The lower $\hat{A R}$ control limit, below which misshelving is unacceptable (see figure 1), can be set by the library manager or computed using two or three standard errors of the $\hat{A R}$ from the $\hat{A R}$ target value. A library manager would probably prefer to set the lower control limit based on management criteria. The $\hat{A R}$ target value and the lower $\hat{A R}$ control limit can be set at the discretion of the library manager as long as the reshelving process is capable of meeting the $\hat{A R}$ target value. Note that an upper control limit is not included because one can never have $\hat{A R}$ estimates greater than one, that is, greater than $100 \%$ accurately shelved books.

\section{Accuracy Ratings from Censused Collections}

From accuracy ratings computed on the four collections we studied (table 2), the Hale Library managers suggested setting the $\hat{A R}$ target values at 0.97 (97\% accuracy) and setting the lower $\hat{A R}$ control limits (LRL) at 0.935 for all collections. These values appear to be reasonable criteria, except possibly for Juvenile Literature. However, Juvenile Literature is a low-priority collection, as its misshelving rate is not as important as the rates of most of the other collections. This is because management efforts are primarily directed at maintaining research-oriented collections.

\section{Example of the Monitoring Approach}

We illustrate our monitoring approach using the anthropology collection at Hale Library (figure 1). The anthropology collection was sampled ten times at three-day intervals (an actual monitoring schedule would use longer interval times). Twenty shelves $(n=20)$ constituting about $14 \%$ of the shelves in the anthropology collection were selected for inspection using SRSWOR. The randomly selected shelves were inspected for misshelved books, using the same misshelving criteria utilized in each of the censuses of the four collec-

\begin{tabular}{|c|c|c|c|c|}
\hline & Anthropology & Juvenile & Mathematics & Science \\
\hline AR & .97 & .93 & .97 & .98 \\
\hline LRL & .93 & .86 & .92 & .96 \\
\hline
\end{tabular}

tions. From each of the ten sets of twenty observed shelves, an $\hat{A R}$ estimate was computed and plotted on the control chart above the appropriate inspection day (figure 1).

No $\hat{A R}$ estimates fell below the lower $\hat{A R}$ control limit, so the process remained in control. In fact, the $A \hat{R}$ estimates remained close to 0.97 as would be expected for a shelving process that is in control and for one that was sampled over a small time interval in a collection that has low usage. The patterns of the $\hat{A R}$ estimates illustrate their inherent variability over the different samples.

The samples of shelf identifiers and the $\hat{A R}$ control chart (figure 1) were generated using a Microsoft Excel 95 spreadsheet program. This program selects a sample of shelves from a list of shelves containing a collection of books. Once the shelves have been inspected, the number of misshelved books (for each shelf inspected) are entered into the spreadsheet. Then the program computes $\hat{A R}$ based on the current inspected sample and generates the $\hat{A R}$ control chart based on all samples. Detailed instructions on constructing and using the program are in Edwardy (1998). The first author should be contacted regarding the program. The main purpose of the spreadsheet program is to "automate" some of the statistical aspects of the sampling and control chart processes.

\section{Recommendations}

We encourage library managers to consider statistical sampling to collect information on the accuracy of reshelving

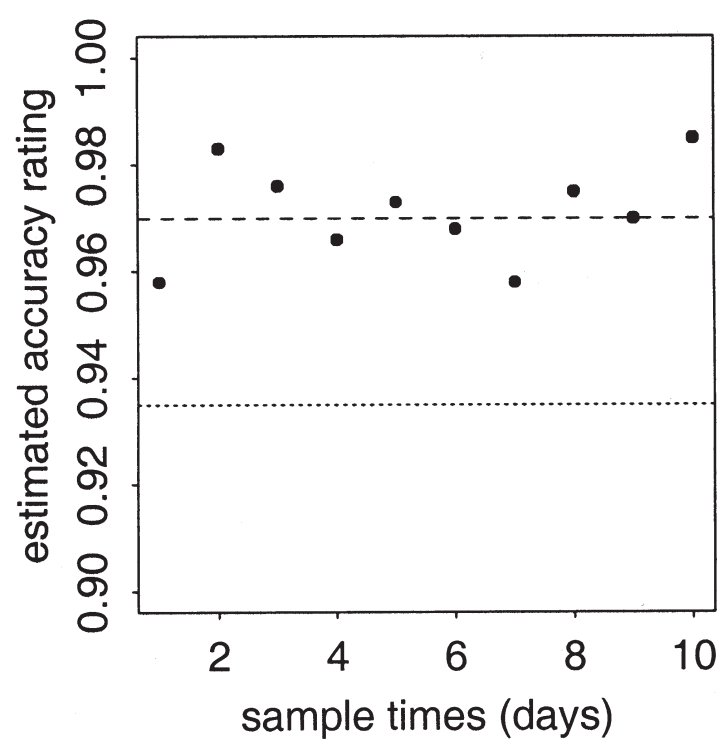

Figure 1. Control Chart of Anthropology Collection 
books. Sampling is more resource-efficient than shelf reading, which is essentially a census, and can provide reliable information given a reasonable sample size. We also encourage library managers to use control charts to decide on acceptable shelving accuracy ratings for their collections and to monitor accuracy ratings over time. Tracking accuracy ratings will provide managers with a "time perspective" on the status of their collections and will provide a signal on when to implement shelf reading based on current and objective information.

An advantage of our sampling and control-chart approach is flexibility. Library managers can tailor our general approach to their specific situations. For example, in a small library, the entire inventory could be considered as one population. Alternatively, stratified random sampling could be used, with one stratum being a collection. Then one control chart could be used for the entire library. A twostage sampling strategy could be used, with cases containing shelves as primary sampling units, and individual shelves within a case as secondary sampling units.

A "collection" may be defined in ways other than subject matter. A collection could be the books overseen by a particular employee, or the collection could be the books in one physical section of the building that houses the library. The definition of a book used here is also somewhat arbitrary and could be defined differently. For example, in bound periodical series on a shelf, the volumes are less likely to be misshelved (or are easier to find than many other books, if on the shelf), and so these could be excluded from the definition of book.

From our evaluations of the four collections in Hale Library, and using several sample sizes $(n)$ proportional to the collections' population sizes, we suggest that a minimum of $10 \%$ of the shelves in a population of shelves be included in a sample. We arrived at this recommendation by considering both the rates of decrease of the standard errors over the four censused collections for various sample sizes and the amount of time that Hale Library employees could devote to inspections for misshelved books. Sample sizes may need to be larger than $10 \%$ or different for different collections depending on the collections' characteristics and the goals of the library managers.

As in shelf reading, the library manager must take care not to specify too large of a sample size to avoid "shelf reading burnout." Reading burnout would introduce measurement errors and likely inflate the variability of the $\hat{A R}$ estimates. The reader can consult Schabo and Breuer Baculis (1989) for some suggestions on avoiding shelf reading burnout.

Personnel performing the sampling inspection should not reshelve misshelved books. Reshelving would increase the amount of time required to complete the inspections, interrupt the focus on inspecting shelves, and subsequently alter the $\hat{A R}$ control chart trend from its natural course. Reshelving should commence after at least one $\hat{A R}$ estimate has fallen below the control chart's lower $\hat{A R}$ limit (e.g., here, 0.935 , figure 1 ).

\section{Works Cited}

Aczel, Amir. 1995. Statistics: Concepts and applications. Chicago: Irwin.

Brase, Charles, and Corrinne Brase. 1998. Understandable statistics: Concepts and methods. Lexington, Mass.: Heath.

Bookstein, A. 1983. Sampling from card files. Library Quarterly 53 (3): 307-312.

Cooper, Michael D., and John Wolthausen. 1977. Misplacement on library shelves: A mathematical model. Library Quarterly 47 (1): 43-57.

DiCarlo, Michael. 1988. Sequential analysis as a sampling test for inventory need. Journal of Academic Librarianship 13 (6): 345-348.

Edwardy, Jeffrey M. 1998. Improving the accuracy of reshelving in libraries through the use of sampling and control charts. M.S. thesis, Kansas State University.

Flexner, J. M. 1927. Circulation work in public libraries. Chicago: ALA.

Fussler, Herman, and Julian Simon. 1969. Patterns in the use of books in large research libraries. Chicago: Univ. of Chicago Pr.

Kendrick, Curtis L. 1991. Performance measures of shelving accuracy. Journal of Academic Librarianship 17 (1): 16-18.

Lohr, Sharon L. 1999. Sampling: Design and analysis. Pacific Grove, Calif.: Duxbury.

Lowenberg, Susan. 1989. A comprehensive shelf reading program. Journal of Academic Librarianship 15 (1): 24-27.

Miller, Bruce, and Marilyn Sorum. 1977. A two stage sampling procedure for estimating the proportion of lost books in a library. Journal of Academic Librarianship 3 (2): 74-80.

Schabo, Pat, and Diana Breuer Baculis. 1989. Speed and accuracy of shelving. Library Journal 114 (16): 67-68.

SPRouTS (Virginia Polytechnic Institute and State University). Available: http://shelving.lib.vt.edu. Accessed Feb. 23, 2001.

Thompson, Steven. 1992. Sampling. New York: Wiley.

Tryfos, Peter. 1996. Sampling methods for applied research. New York: Wiley. 